\title{
Serum lactate dehydrogenase (LDH) level in mild and severe preeclampsia as a prognostic marker
}

\author{
Radheshyam Bairwa, Suhail Iqbal*
}

Department of Obstetrics and Gynecology, Jhalawar Medical College, Jhalawar, Rajasthan, India

Received: 04 September 2018

Accepted: 17 September 2018

\section{*Correspondence:}

Dr. Suhail Iqbal,

E-mail: isuhaillove@gmail.com

Copyright: (C) the author(s), publisher and licensee Medip Academy. This is an open-access article distributed under the terms of the Creative Commons Attribution Non-Commercial License, which permits unrestricted non-commercial use, distribution, and reproduction in any medium, provided the original work is properly cited.

\begin{abstract}
Background: Lactate Dehydrogenase (LDH) is mainly an intracellular enzyme. Its level is an useful biomarker for cellular injury which may suggested as a potential marker to predict the severity of preeclampsia and indicator for multi-organ involvement have significant role in management of preeclampsia. We conducted this study to examine the relationship between lactate dehydrogenase concentration and the severity of the disease and occurrence of complications. The objective of the present study was to assess role of serum LDH level in mild and severe preeclamptic women

Methods: This prospective study was conducted in the Department of obstetrics and gynecology in Jhalawar medical college from Jan 2017 to Oct 2017 Total 120 pregnant women during third trimester (32-40 weeks) aged 18 to 35 years were selected. Among them 40 were severe preeclampsia and 40 were mild preeclampsia patients and 40 were healthy normotensive control. Serum LDH level was estimated by continuous spectrophotometric method. Demographic, hemodynamic, and laboratory data were compared among the three groups. The symptoms and complications of severe pre-eclampsia along with foetal outcome were analyzed according to the levels of LDH.

Results: In this study, serum LDH level was significantly higher $(\mathrm{P}<0.001)$ in preeclamptic compared to those of control. Again, this value was significantly higher in severe preeclamptic than those of mild preeclamptic. The symptoms and complications of preeclampsia along with perinatal mortality were increased significantly in patents with $\mathrm{LDH}>800 \mathrm{IU} / \mathrm{I}$ compared with those who had lower levels.

Conclusions: From this study, it can be concluded that elevated serum LDH level is associated with severity of preeclampsia. $\mathrm{LDH}$ has been evaluated as a biochemical marker for preeclampsia and as a prognosticator of the disease severity. Detection of high-risk patients with increased levels of LDH mandate close monitoring and management to prevent maternal and fetal morbidity and mortality.
\end{abstract}

Keywords: Maternal morbidity, Maternal mortality, Serum LDH, Severe preeclampsia

\section{INTRODUCTION}

Pregnancy is a physiological state associated with many alterations in metabolic, biochemical, physiological, hematological and immunological processes. If there are no complications, all these changes are reversible following a few days to a few months after delivery. ${ }^{1}$ Hypertension during pregnancy is a major health problem. Preeclampsia (PE) is a theoretical disease with a pathogenesis that is not clearly understood yet. Lately vascular system pathology and vasoconstriction have been blamed as causes for preeclampsia. Preeclampsia is a condition of hypertension (> 140/90 mm Hg) associated with proteinuria and oedema in pregnant women after the 20th gestational week and most frequently near term. ${ }^{1}$

Preeclampsia can be categorized in to mild and severe forms. ${ }^{2}$ Mild preeclampsia is defined as onset of 
hypertension after 20 weeks of gestation with systolic blood pressure of $>140$ to $<160 \mathrm{mmHg}$ or a diastolic blood pressure $>90$ to $<110 \mathrm{mmHg}$ in combination with proteinuria $>0.3 \mathrm{gm}$ to $<5 \mathrm{gm}$ per day.

Severe preeclampsia is diagnosed when systolic blood pressure is greater than $160 \mathrm{mmHg}$ or diastolic blood pressure is greater than $110 \mathrm{mmHg}$ and associated with proteinuria greater than or equal to $5 \mathrm{gm}$ per day. Severe preeclampsia is accompanied by thrombocytopenia, pulmonary oedema, or oliguria. ${ }^{2-3}$

Preeclampsia is a major cause of maternal and perinatal morbidity and mortality. ${ }^{4}$ Preeclampsia virtually affects all maternal organ system including liver, kidneys, brain, clotting system and primarily the placenta. ${ }^{5-6}$ Defective placentation and endothelial dysfunction are considered as the core features of preeclampsia. ${ }^{7-8}$

Literature review suggested that in preeclampsia the progressive endothelial dysfunction in maternal vascular system induced by toxins released from hypoxic placenta causes profound vasoconstriction affecting all organ system including liver.

This hypo-perfusion induced ischemic injury to the hepatic cells and other organs causes increased release of cellular LDH into serum and also paranchymal necrosis of liver causes elevation of hepatic enzymes (AST and ALT>70 IU/L, LDH>600IU/L). ${ }^{9}$ Lactate dehydrogenase is an intracellular enzyme and its elevated blood level indicates cellular death followed by its leakage to circulation. ${ }^{6,10}$ Recently, LDH level has been suggested as potential markers to predict the severity of preeclampsia and indicator for multiorgan involvement. ${ }^{6}$

Several studies reported that serum LDH level increases with severity of preeclampsia and showed significant correlation with high blood pressure and poor maternal and perinatal outcomes. In their study, the symptoms and complications of preeclampsia along with perinatal mortality were significantly increased in patients with serum LDH > 800 IU/L. ${ }^{5-6,8,10}$

Moreover, the serum LDH was found a good predictor of the severity of pregnancy induced hypertension (PIH) and bad foetal outcome. But some researchers did not find significant difference of serum LDH level between preeclamptic women and healthy pregnant women. ${ }^{11-12}$ Therefore, the present study has been designed to assess the serum LDH level in pregnant women with mild and severe preeclampsia.

\section{METHODS}

This prospective study was conducted in the Department of obstetrics and gynecology in Jhalawar Medical College from Jan 2017 to Oct 2017. All of the subjects were selected from Department of Obstetrics and Gynecology of Jhalawar Medical College Hospital
Rajasthan by simple random sampling. After selection the nature, purpose, benefit and risks of the study were explained in detail. Informed written consent was taken from the participants. Before taking blood, detailed family and medical history were taken and recorded in a prefixed data schedule.

Serum LDH level was estimated by continuous spectrophotometric method. Presence of proteinuria was determined by conventional heat coagulation test. Then interpretation of the heat coagulation test result was done according to presence of turbidity in the urine as nil/ trace (0), 1+, 2+, 3+ and 4+.

\section{Inclusion criteria}

- $\quad$ Singleton pregnancy

- Age 18-35 years,

- Preeclamptic women whose blood pressure was normal during first 20 weeks of gestation

- No previous history of hypertension and all the case were in the third trimester of pregnancy.

\section{Exclusion criteria}

- Patients with diabetes, renal failure, haemolytic anemias, chronic hypertension, gestational diabetes, multiple pregnancy, smoking and alcoholism, liver disease, hepatotoxic drugs, stroke, coronary artery disease, chronic lung diseases, connective tissue disorders, disseminated intravascular coagulation and seizures, were excluded.

\section{Statistical analysis}

Sample size included total of 120 pregnant women during third trimester (32-40 weeks) aged 18 to 35 years were selected. The patients were divided into three groups: group I $(n=40)$ - third-trimester healthy pregnant women, group II $(\mathrm{n}=40)$ women with mild pre-eclampsia, and group III $(n=40)$ patients with severe pre-eclampsia.

The three groups were matched according to age, gravidity, parity, maternal weight, and hemodynamic and laboratory results. Because levels of LDH <600 IU/1 are common in normal pregnancy and only levels $>600 \mathrm{IU} / 1$ were reported to be associated with complicated preeclampsia. Stastical analysis of data is done by help of SPSS 20.0 Software (trail version). Chi square test, Unpaired - T test, Correlation and One-way ANOVA test is use in data analysis.

\section{RESULTS}

In present study the total 120 patients were taken, divided into 3 groups, each group containing 40 patients. The groups were divided into severe pre-eclampsia, mild preeclampsia and 40 patients who were not having increased bp or proteinuria were allocated to control group. The age group which we took for our study was 
between 18 to 35years. The mean age for severe preeclampsia was 23.6000 \pm 3.09 . The mean age for mild preeclampsia was $24.2500 \pm 2.98$, and the mean age for control group was $24.8000 \pm 3.74$. The $\mathrm{P}$ value was 0.268 which is more than 0.05 so the null hypothesis was not rejected .so there was no significant correlation found between age and preeclampsia.

Table 1: Distribution of age according to the groups.

\begin{tabular}{|llllll|} 
& N & $\begin{array}{l}\text { Mean } \\
\text { age }\end{array}$ & $\begin{array}{l}\text { Std. } \\
\text { deviation }\end{array}$ & $\begin{array}{l}\text { F } \\
\text { value }\end{array}$ & $\begin{array}{l}\text { P } \\
\text { value }\end{array}$ \\
\begin{tabular}{|l} 
Severe pre- \\
eclampsia
\end{tabular} & 40 & 23.6000 & 3.09507 & & \\
\hline $\begin{array}{l}\text { Mild pre- } \\
\text { eclampsia }\end{array}$ & 40 & 24.2500 & 2.98501 & 1.332 & 0.268 \\
\hline Normal & 40 & 24.8000 & 3.74303 & & \\
\hline Total & 120 & 24.2167 & 3.30058 & & \\
\hline
\end{tabular}

In present study total 120 patients were taken according to parity, divided into 7 groups which are G2A1, G2P1L0, G2P1L1， G3P2L1， G3P2L2,G4L3P3 and primigravidas group for which $(\mathrm{N}=1,2,20,1,6,1,89)$ $(0.80 \%, 1.70 \%, 16.70 \%, 0.80 \%, 5.00 \%, 0.80 \%, 74.20 \%)$ chi square value is 15.606 and $\mathrm{P}$ value is 0.210 which is more than 0.05 so null hypothesis was not rejected so there is no significant correlation found between parity and preeclampsia.

The total 120 patients who were divided into 3 groups i.e. severe, mild preeclampsia and control group. the patients were allocated to each group according to their mean bp. The severe preeclampsia group was having a mean bp of $170.35 \pm 10.56$, the mild preeclampsia group was having bp of $144.5000 \pm 6.05$, the control group was having a

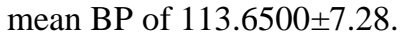

Table 2: Distribution of parity according to the groups.

\begin{tabular}{|c|c|c|c|c|c|c|}
\hline \multirow[b]{2}{*}{ Parity } & \multicolumn{3}{|l|}{ Group } & \multirow{2}{*}{ Total } & \multirow{2}{*}{ Chi sq } & \multirow[t]{2}{*}{ P value } \\
\hline & Severe pre-eclampsia & Mild pre-eclampsia & Normal & & & \\
\hline \multirow{2}{*}{ G2 A1 } & 0 & 1 & 0 & 1 & \multirow{15}{*}{15.606} & \multirow{15}{*}{0.210} \\
\hline & $0.00 \%$ & $2.50 \%$ & $0.00 \%$ & $0.80 \%$ & & \\
\hline \multirow{2}{*}{ G2P1L0 } & 1 & 1 & 0 & 2 & & \\
\hline & $2.50 \%$ & $2.50 \%$ & $0.00 \%$ & $1.70 \%$ & & \\
\hline \multirow{2}{*}{ G2P1L1 } & 3 & 8 & 9 & 20 & & \\
\hline & $7.50 \%$ & $20.00 \%$ & $22.50 \%$ & $16.70 \%$ & & \\
\hline \multirow{2}{*}{ G3P2L1 } & 1 & 0 & 0 & 1 & & \\
\hline & $2.50 \%$ & $0.00 \%$ & $0.00 \%$ & $0.80 \%$ & & \\
\hline \multirow{2}{*}{ G3P2L2 } & 0 & 2 & 4 & 6 & & \\
\hline & $0.00 \%$ & $5.00 \%$ & $10.00 \%$ & $5.00 \%$ & & \\
\hline \multirow{2}{*}{ G4P3L3 } & 0 & 0 & 1 & 1 & & \\
\hline & $0.00 \%$ & $0.00 \%$ & $2.50 \%$ & $0.80 \%$ & & \\
\hline \multirow{2}{*}{ Primi } & 35 & 28 & 26 & 89 & & \\
\hline & $87.50 \%$ & $70.00 \%$ & $65.00 \%$ & $74.20 \%$ & & \\
\hline Total & $100.00 \%$ & $100.00 \%$ & $\begin{array}{l}40 \\
100.00 \%\end{array}$ & $\begin{array}{l}120 \\
100.00 \%\end{array}$ & & \\
\hline
\end{tabular}

Table 3: Distribution of blood pressure according to groups.

\begin{tabular}{|llllll|}
\hline & N & Mean BP & Std. deviation & F value & P value \\
\hline Severe Pre-eclampsia & 40 & 170.3500 & 10.56251 & & $<0.0001$ \\
\hline Mild Pre-eclampsia & 40 & 144.5000 & 6.05932 & 480.203 & \\
\hline Normal & 40 & 113.6500 & 7.28733 & & $<0.0001$ \\
\hline Total & 120 & 142.8500 & 24.65311 & & \\
\hline Severe Pre-eclampsia & 40 & 113.8250 & 5.37748 & 466.393 & \\
\hline Mild Pre-eclampsia & 40 & 94.9000 & 6.12603 & & \\
\hline Normal & 40 & 74.4500 & 5.77328 & & \\
\hline Total & 120 & 94.3917 & 17.12892 & & \\
\hline
\end{tabular}

The systolic blood pressure was significantly higher in severe preeclampsia followed by mild preeclampsia and normal patients. The diastolic blood pressure also shows similar results. In present study the total 120 patients were taken, divided into 3 groups, each group containing 40 patients. The groups were divided into severe preeclampsia, mild preeclampsia and 40 patients who were not having increased B.P or proteinuria were allocated to 
control group. The mean urine albumin for severe preeclampsia was $1.4725 \pm 0.25$. The mean urine albumin for mild pre-eclampsia was $0.3925 \pm 0.18$, and the mean urine albumin for control group was $0.1530 \pm 0.60$. The mean uric acid for severe pre-eclampsia was $6.8700 \pm 0.86$. The mean uric acid for mild pre-eclampsia was $4.6750 \pm 1.21$, and the mean urine albumin for control group was $3.1690 \pm 0.33$.

Table 4: Distribution of urine-albumin and uric-acid according to groups.

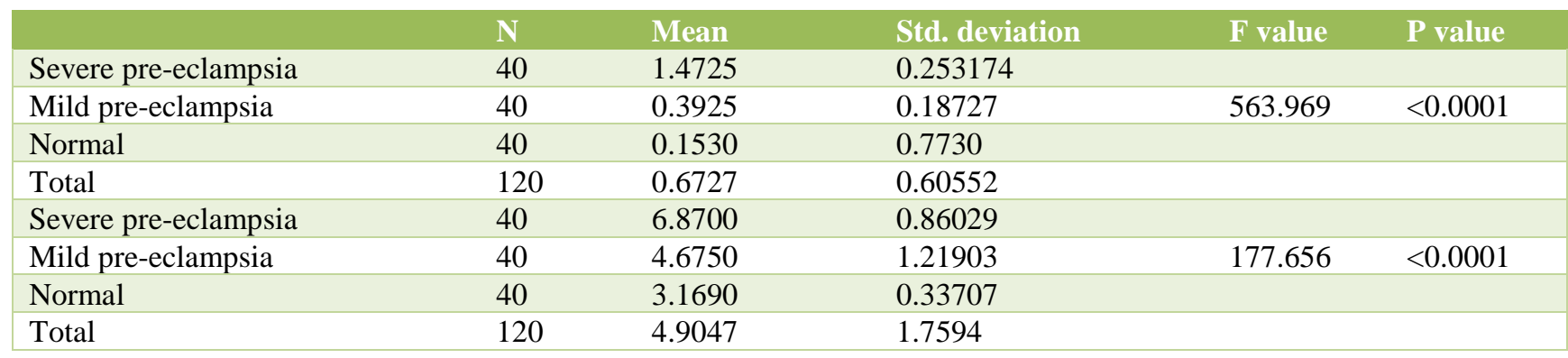

Table 5: Distribution of LDH according to the groups.

\begin{tabular}{|llllll|}
\hline & N & Mean Serum LDH & Std. Deviation & F value & P value \\
\hline Severe pre-eclampsia & 40 & 550.1000 & 518.17892 & & \\
\hline Mild pre-eclampsia & 40 & 445.8500 & 65.99167 & 53.975 & $<0.0001$ \\
\hline Normal & 40 & 243.8750 & 43.97213 & & \\
\hline Total & 120 & 413.2750 & 184.27400 & & \\
\hline
\end{tabular}

Table 6: Distribution of mode of delivery according to groups.

\begin{tabular}{|c|c|c|c|c|c|}
\hline \multirow[b]{2}{*}{ Mode of delivery } & \multicolumn{3}{|l|}{ Group } & \multirow{2}{*}{ Total } & \multirow{2}{*}{ Chi sq } \\
\hline & Severe pre-eclampsia & Mild pre-eclampsia & Normal & & \\
\hline \multirow{2}{*}{ LSCS } & 21 & 11 & 4 & 36 & \\
\hline & $52.60 \%$ & $27.50 \%$ & $10.00 \%$ & $30.00 \%$ & \\
\hline \multirow{2}{*}{ NVD } & 10 & 29 & 36 & 84 & 17.381 \\
\hline & $47.50 \%$ & $72.50 \%$ & $90.00 \%$ & $70.00 \%$ & \\
\hline Total & 40 & 40 & 40 & 120 & \\
\hline
\end{tabular}

So, the women with severe pih showed statistically significant increase in terms of urine albumin $(\mathrm{P}<0.0001)$ And uric acid $(\mathrm{P}<0.0001)$. The mean serum $\mathrm{LDH}$ for severe pre-eclampsia was $550.1000 \pm 5181.17$. The mean Serum LDH for mild pre-eclampsia was 445.8500 \pm 65.99 , and the mean serum for control group was 243.875 \pm 43.97 . Hence, Women with severe pih showed statistically significant increase in terms of Serum LDH ( $\mathrm{P}<0.0001)$. Out of 120 patients which were divided into severe preeclampsia, mild preeclampsia and control group ;36 patients underwent caesarian section and 84 had normal vaginal deliveries but out of 36 caesarian sections 21 were from severe preeclampsia group, 11 from mild preeclampsia group and 4 from control group.

Table 7: Distribution of $\mathrm{LDH}$ and birth weight in severe pre-eclampsia groups.

\begin{tabular}{|lllll|l|} 
& Mean & Std. Deviation & N & r value & P value \\
\hline Birth Weight & 1.9125 & 0.46585 & 40 & & \\
\hline Serum LDH & 550.1000 & 218.17892 & 40 & -0.585 & $<0.0001$ \\
\hline
\end{tabular}

In our study we found there was number of Caesarean sections more than normal vaginal delivery in severe preeclampsia in comparison to mild preeclampsia and normal patients. $(\mathrm{P}$ value $=0.0001$ which is less than 0.05 so null hypothesis was rejected so there is significant correlation found between severity of preeclampsia and 
rate of cesarean section.). The distribution of $\mathrm{LDH}$ and Birth weight was analysed in a severe preeclampsia group of 40 patients $(\mathrm{N}=40)$ and it was found that with increase in serum $\mathrm{LDH}$ values there was decrease in birth weight.
Hence In present study we found there is a negative correlation between birth weight and serum LDH level in severe preeclampsia $(\mathrm{r}$ value $=-0.585)$. $(\mathrm{P}$ value $<0.0001)$.

Table 8: Distribution of according to the groups.

\begin{tabular}{|llllll} 
& Perinatal death & N & Mean serum LDH & Std. deviation & T value \\
\multirow{2}{*}{ Serume LDH } & Present & 10 & 749.8000 & 105.09445 & 3.905 \\
\cline { 2 - 5 } & Absent & 30 & 483.5333 & 205.55572 & \\
\hline
\end{tabular}

In present study out of 40 patients which belonged to the severe preeclampsia group ,10 perinatal deaths occurred and, in these patients, mean serum LDH levels were found to be higher (mean serum $\mathrm{LDH}=749.8000 \pm 105.094)$ as compared to other 30 patients having lower mean LDH values (mean serum $\mathrm{LDH}=483.5333 \pm 205.55) . \quad(\mathrm{T}$ value $=3.905, \mathrm{P}$ value $<0.0001$ which is less than 0.05 , thus significant correlation is found between perinatal death and serum LDH values).

\section{DISCUSSION}

In present study, we observed a significant rise in the LDH levels with increasing severity of the disease ( $\mathrm{P}$ $<0.0001$-statistically significant). Mean LDH level in control is $243.87 \pm 43.9$, mean LDH level in mild preeclampsia is $445.85 \pm 66$ and in severe preeclampsia is 550.1 \pm 218.17 . Study by Qublan HS et al also demonstrated a significant association of serum LDH levels with severe preeclampsia $(\mathrm{P}<0.001) .{ }^{11}$

In another study by Jaiswar SP et al mean LDH levels of control group was $278.3 \pm 119.2$ IU/l (normotensives), 13 in mild preeclampsia group it was $400.45+145.21 \mathrm{IU} / 1$ and in severe preeclampsia group it was $646.95 \pm 401.64$ IU/l. There is reduction in the average weight of babies with higher level of LDH. This indicates increase in preterm deliveries in patients with higher LDH levels in the present study. This is in accordance with the study done by Umasatyasri $\mathrm{Y}$ et al. ${ }^{14}$

In the present study, increased serum LDH level in preeclamptic women than control women are attributed to these facts. Moreover, the progressively increased LDH level in severe preeclampsia indicates progression of cellular injury with severity of this disorder. Moreover, in our study we found there was number of Caesarean sections more than normal vaginal delivery in severe preeclampsia in comparison to mild preeclampsia and normal patients. $(\mathrm{P}$ value $=0.0001$ which is less than 0.05 so null hypothesis was rejected so there is significant correlation found between severity of preeclampsia and rate of cesarean section), and more perinatal deaths occurred in patients with higher LDH values.

\section{CONCLUSION}

From the results of this study, it can be concluded that elevated serum LDH level is associated with severity of preeclampsia. In the present study, LDH has been evaluated as a biochemical marker for preeclampsia and as a prognosticator of the disease severity. Detection of high-risk patients with increased levels of LDH mandate close monitoring and management to prevent maternal and fetal morbidity and mortality.

\section{ACKNOWLEDGMENTS}

Authors would like to express gratitude to the participants of the study and to the authorities of Jhalawar Medical College for their kind permission to carry out the study. Special thanks to DR U. S. Shukla (Associate Professor, Statistics).

\section{Funding: No funding sources}

Conflict of interest: None declared

Ethical approval: The study was approved by the Institutional Ethics Committee

\section{REFERENCES}

1. Reynolds C, Mabie WC, Sibai BB. Current Obstetric and Gynecologic Diagnosis and Treatment. 9th ed. New York: The McGraw-Hill Companies; c2003. Chapter 19, Hypertensive States of Pregnancy; p. 338-353.

2. Anjana S, Poonam M, Shradha B. Management of pregnancy induced hypertension. IJRAP. 2010;1(2):390-8.

3. Sarkar PD, Sogani S. Evaluation of serum lactate dehydrogenase and gamma glutamyl transferase in preeclamptic pregnancy and its comparison with normal pregnancy in third trimester. Int J Res Med Sci. 2013;1(4):365-8.

4. Munde SM, Hazari NR, Thorat AP, Gaikwad SB, Hatolkar VS. Gamma glutamyl transferase and Lactate dehydrogenase as biochemical markers of severity of preeclampsia. Int $\mathrm{J}$ Med Health Pharm Biomed Eng. 2014;8(1):50-3. 
5. Babu R, Venugopal B, Sabitha K, Ravikiran BS, Reddy EP. Comparative study of liver and kidney biochemical parameters in normal and pre-eclamptic gestation. J Curr Trends Clin Med Lab Biochemistry. 2013;1(3):26-30.

6. Jaiswar SP, Amrit G, Rekha S, Natu SN, Mohan S. Lactic dehydrogenase: A biochemical marker for preeclampsia-eclampsia. J Obstet Gynaecol India. 2011;61(6):645-8.

7. Bera S, Gupta S, Roy SS, Kunti S, Biswas S, Ghosh D. Study of liver enzymes especially lactate dehydrogenase to predict foetal outcome in pregnancy induced hypertension. Sch J App Med Sci. 2014;2(5A):1569-72.

8. Dutta DC. Text Book of Obstetrics. $6^{\text {th }}$ ed. Calcutta: New Central Book Agency (P) Ltd; 2008: 666.

9. Dutta DC. Text Book of Obstetrics. $8^{\text {th }}$ ed. Calcutta: Jaypee Brothers Medical Publishers (p) Ltd; 2013: 258.

10. Wagner LK. Diagnosis and management of preeclampsia. Am Fam Physician. 2004;70(12)231724.
11. Nosrat BS, Azarhoosh R, Borghei A, Sedaghati M. Besharat S, Ghaemi E. Serum level of lactate dehydrogenase, homocysteine, hemoglobin and platelets in preeclampsia. Pak $\mathrm{J}$ Med Sci. 2011;27(5):1014-7.

12. Gruccio S, Di Carlo MB, Pandolfo M, Cruza GS, Touzona MS, Negria G, et al. Biochemical profiling study in umblical cord blood as a predictor of neonatal damage. Int J Clin Pediatr. 2014;3(1):5-11.

13. Jaiswer SP, Gupta A. Lactate dehydrogenase as a biochemical marker for preeclampsia eclampsia. JOGI. 2011;61(6):645-8.

14. Umasatyasri Y. Role of $\mathrm{LDH}$ in preeclampsia marker: an observational study; IAIM. 2015;2(9):8893.

Cite this article as: Bairwa $\mathrm{R}$, Iqbal $\mathrm{S}$, Serum lactate dehydrogenase (LDH) level in mild and severe preeclampsia as a prognostic marker. Int J Reprod Contracept Obstet Gynecol 2018;7:3969-74. 